\title{
Characterisation of the bacterial community in expressed prostatic secretions from patients with chronic prostatitis/chronic pelvic pain syndrome and infertile men: a preliminary investigation
}

\author{
Dong-Sheng Hou ${ }^{1,2, *}$, Wen-Min Long ${ }^{3, *}$, Jian Shen ${ }^{1,2}$, Li-Ping Zhao ${ }^{3}$, Xiao-Yan Pang ${ }^{3}$ and Chen Xu ${ }^{1,2}$
}

The expressed prostatic secretions (EPSs) of men with chronic prostatitis/chronic pelvic pain syndrome (CP/CPPS), infertile men and normal men were subjected to microbiological study. EPSs were collected from the subjects, which included 26 normal men, 11 infertile patients and 51 CP/CPPS patients. DNA was extracted from each specimen, and the V3 regions of the 16S rRNA genes were amplified using universal bacterial primers. The results showed that the EPS 16S rRNA gene-positive rate in the CP/CPPS and infertile patients was much higher than in the normal men, but without any difference among the three patient groups. The denaturing gradient gel electrophoresis (DGGE) method was used to characterize the EPS bacterial community structure of the prostate fluid from patients with CP/CPPS or infertility issues. Principal component analysis (PCA) and partial least squares (PLS) analyses of PCR-DGGE profiles revealed that the EPS bacterial community structure differed among the three groups. Three bands were identified as the key factors responsible for the discrepancy between CP/CPPS patients and infertile patients $(P<0.05)$. Two bands were identified as priority factors in the discrepancy of category IIIA and category IIIB prostatitis patients $(P<0.05)$. According to this research, the ecological balance of the prostate and low urethra tract, when considered as a microenvironment, might play an important role in the maintenance of a healthy male reproductive tract.

Asian Journal of Andrology (2012) 14, 566-573; doi:10.1038/aja.2012.30; published online 28 May 2012

Keywords: bacteria; chronic prostatitis/chronic pelvic pain syndrome; denaturing gradient gel electrophoresis; prostatitis

\section{INTRODUCTION}

Chronic prostatitis is a common disease in men. It has been estimated that up to half of all men suffer from prostatitis symptoms at some point in their lives. ${ }^{1,2}$ This disease was defined using four categories, ${ }^{3}$ with most of the patients being characterized as having chronic prostatitis/chronic pelvic pain syndrome (CP/CPPS), which is also known as category III prostatitis. ${ }^{4} \mathrm{CP} / \mathrm{CPPS}$ includes two subgroups: $\mathrm{CP} /$ CPPS with inflammation (category IIIA prostatitis) and CP/CPPS without inflammation (category IIIB prostatitis). As one of the most common and puzzling diseases seen at the outpatient department of urology, chronic prostatitis is characterized by a high prevalence, low cure rate, frequent recurrence and severe impairment in terms of the quality of life. Treatment of this disease is costly. ${ }^{5}$ Epidemiologic study has suggested that chronic prostatitis is correlated with an increased risk of benign prostatic hyperplasia and prostate cancer. ${ }^{6,7}$ Although chronic prostatitis is one of the important factors affecting male reproductive health, the exact aetiology of the disease remains unknown. ${ }^{8}$

The traditional culture method plays an important role in detecting bacteria inhabiting the male reproductive tract. However, this method is time-consuming and labour-intensive, with no suitable culture medium for most of the bacteria that exist in the human body. This makes it difficult to detect bacteria in the lower urinary tract. ${ }^{9}$ Due to limitations of the traditional culture method, we used the cultureindependent method in this research. Actually, this method has already been used successfully in exploring bacterial communities in some parts of the human body, ${ }^{10-13}$ and it has been proven successful in detecting various types of bacteria inhabiting the human body. Using this advanced method, studies have been performed to investigate the bacteria living in prostate biopsies and EPS specimens. The results indicate that the existence of bacteria correlates with male reproductive health. ${ }^{14-17}$

Expressed prostatic secretions (EPSs) were used as the study samples, because EPSs are produced from the prostate and acquire bacteria, while they pass through the urethra. This body fluid could reflect the composition of bacterial communities inhabiting the prostate and the urethra. We explored the EPS bacterial community composition using the molecular fingerprint method: polymerase chain reactiondenaturing gradient gel electrophoresis (PCR-DGGE). This method

${ }^{1}$ Department of Histology and Embryology, Shanghai Jiao Tong University School of Medicine, Shanghai 200025, China; ${ }^{2}$ Shanghai Key Laboratory of Reproductive Medicine, Shanghai 200025, China and ${ }^{3}$ National Key Laboratory of Microbial Metabolism, College of Life Science and Biotechnology, Shanghai Jiao Tong University, Shanghai 200025, China

* These authors contributed equally to this work.

Correspondence: Dr C Xu (chenx1955@126.com) or Dr XY Pang (xypang@sjtu.edu.cn)

Received: 15 December 2011; Revised: 6 February 2012; Accepted: 29 February 2012; Published online: 28 May 2012 
allows for the simultaneous analysis of multiple samples in one gel, and it has been proven effective in elucidating the diversity of the bacterial community living in the human body. ${ }^{13,18}$ Using a cultivation-independent method, we investigated the EPS bacterial community composition in four subject groups: normal men, CP/CPPS patients with and without inflammation and infertile patients, to find out whether differences in the composition of the EPS bacterial community were related to male reproductive health.

\section{MATERIALS AND METHODS}

\section{Case selection and patient details}

The study protocol and informed consent documents were reviewed and approved by the Ethical Review Board of the Shanghai Jiao Tong University School of Medicine. Informed consent from all subjects was documented before participation in this study. The first group consisted of normal men who were sperm donors without any CP/CPPS symptoms $(n=26)$. The inclusion criteria for CP/CPPS patients were as follows: (i) willing to sign an informed consent form and participate in this study; (ii) having at least one of the following symptoms: persistent peritoneal pain (some CPPS patients reported the perineum as the sole location of pelvic pain); functional and somatic urologic complaints, including abnormal urine flow, frequency, urgency, dysuria and sexual disturbance; (iii) symptoms lasting at least 3 months; and (iv) a well-developed genital system. The exclusion criteria were as follows: (i) not willing to sign the informed consent form; (ii) an abrupt onset of fever and genitourinary and constitutional signs and symptoms; (iii) reports of a recurrent UTI and persistence of bacteria in the prostatic secretory system despite multiple courses of antibacterial therapy; (iv) previous surgery on the prostate and urethra; (v) systemic disease; and (vi) use of OTC or prescription antibiotics within the past 4 weeks. With these inclusion and exclusion criteria, patients with recurrent infection and with prostate fluid culture samples that yielded positive results were considered to have chronic bacterial prostatitis (category II prostatitis). These types of patients were excluded from our research. According to the inflammation condition, the CP/CPPS patients could be separated into two types: (i) $\mathrm{CP} / \mathrm{CPPS}$ patients with inflammation (category IIIA) had leukocytes in the EPS (the white blood cell count was more than 10 white blood cells per high-power microscopic field); and (ii) CP/CPPS patients without any signs of inflammation (category IIIB) (the white blood cell count was less than 10 white blood cells per high-power microscopic field). ${ }^{19,20}$ The fourth group was infertile patients, including seven patients with asthenospermia, one patient with necrospermia, one patient with azoospermia, one patient with oligozoospermia and one patient with semen liquification problems. These infertile patients were diagnosed with no symptoms of prostatitis and without any evidence of inflammation.

\section{Specimen collection}

Prior to sample collection, subjects were instructed on how to prevent contamination throughout the process. The penis was cleaned with warm soapy water and a $75 \%$-alcohol tampon $(\sim 2-3$ times $)$. The cotton swab used for the skin outside the urethra was taken and collected in a $10-\mathrm{ml}$ sterile tube. Each subject received a prostate massage. EPS was collected with a $5.0-\mathrm{ml}$ sterile tube. The EPS was dropped directly into a tube, avoiding contact with the interior of the sterile wall of the container. A routine EPS test was performed with one drop of the EPS collected. The rest of the EPS and the swab were stored at $-80{ }^{\circ} \mathrm{C}$ within $2 \mathrm{~h}$ for subsequent DNA extraction.

\section{DNA extraction}

DNA was extracted from each EPS and the cotton swab using the beadbeating method. ${ }^{21}$ The specimens were transferred to a sterile $2-\mathrm{ml}$ tube and stored on ice. The volume was adjusted to $500 \mu \mathrm{l}$ with TE buffer ( $\mathrm{pH} 8.0$ ). The samples were initiated by adding $50 \mu$ lysozyme $\left(10 \mathrm{mg} \mathrm{ml}^{-1}\right), 6 \mu \mathrm{l}$ mutanolysin $\left(25000 \mathrm{U} \mathrm{ml}^{-1}\right.$; Sigma-Aldrich, St Louis, MO, USA) and $3 \mu$ lysostaphin $\left(4000 \mathrm{U} \mathrm{ml}^{-1}\right.$ in sodium acetate; Sigma-Aldrich) and $41 \mu \mathrm{l}$ TE50 buffer $\left(10 \mathrm{mmol}^{-1}\right.$ TrisHCL, $50 \mathrm{mmol} \mathrm{l}^{-1}$, EDTA, pH 8.0). This was followed by 1-h-long incubation at $37^{\circ} \mathrm{C}$ in a water bath. The cells were then disrupted by bead beating, which was performed with bleached and rinsed with $0.1-\mathrm{mm}$ diameter zirconia/silica beads (BioSpec Products, Bartlesville, OK, USA), for $1 \mathrm{~min}$ at room temperature, with 36 oscillations/s in a Mini-Beadbeater-96 (BioSpec Products). The resulting crude lysate was processed using the QIAamp DNA Mini Kit (Qiagen, Valencia, CA, USA) according to the manufacturer's recommendations. The samples were eluted with $50 \mu \mathrm{l} \mathrm{AE}$ buffer into separate tubes. The samples were stored at $-80{ }^{\circ} \mathrm{C}$.

\section{PCR amplification of the extracted DNA}

The $\mathrm{V} 3$ regions of the $16 \mathrm{~S}$ rRNA genes were amplified using universal bacterial primers (341F: 5'-GTATTACCGCGGCTGCTGG-3'; 534R: $5^{\prime}$-ACTCCTACGGGAGGCAGCAG-3') for all of the samples collected. The protocol for the PCR procedure was that reported by Muyzer. ${ }^{22}$ We first performed PCR for the cotton swab DNA of each subject. PCR products of the amplified products were checked by electrophoresis on $1.2 \%(\mathrm{w} / \mathrm{v})$ agarose gel and visualized by ethidium bromide staining. Almost all of the cotton swabs were $16 \mathrm{~S}$ rRNA genenegative. Any subject for whom the cotton swab was $16 \mathrm{~S}$ rRNA genepositive was excluded from our research. DNA concentrations were measured using a NanoDrop ND-1000 spectrophotometer (Thermo Electron Corporation, Waltham, MA, USA). All amplified products were stored at $-20^{\circ} \mathrm{C}$ before DGGE analysis.

\section{PCR-DGGE}

For DGGE analysis, a 40-bp GC clamp (5'-CGCCCGCCGCGCGCGGCGGGCGGGGCGGGGGCACGGGGGG-3') was attached to the $5^{\prime}$ ends of the reserve primers. The touchdown protocol was used in conjunction with the PCR procedure being described by Muyzer. ${ }^{22}$ The reaction mixture contained 1.25 units of Hot Start Taq polymerase (Takara, Dalian, China), $12.5 \mu$ l of $2 \times$ PCR buffer, 5 pmol of each primer, $200 \mathrm{mmol}^{-1}$ of each deoxynucleoside triphosphate (dNTP), and $30 \mathrm{ng}$ of extracted bacterial DNA. The total PCR reaction volume was $25 \mu \mathrm{l}$. The thermal cycling program included the following time and temperature profile: $94{ }^{\circ} \mathrm{C}$ for $5 \mathrm{~min} ; 40$ cycles of touchdown PCR: denaturation at $95{ }^{\circ} \mathrm{C}$ for $30 \mathrm{~s}$, annealing at $65{ }^{\circ} \mathrm{C}$ for $30 \mathrm{~s}$ with the temperature decreasing by $0.5^{\circ} \mathrm{C}$ every second cycle until the annealing temperature was $55^{\circ} \mathrm{C}$, and extension at $72^{\circ} \mathrm{C}$ for $30 \mathrm{~s}$; then, an additional 5 cycles with annealing temperature at $55^{\circ} \mathrm{C}$ for $30 \mathrm{~s}$ were performed; this was followed by final extension at $72{ }^{\circ} \mathrm{C}$ for $5 \mathrm{~min}$. To decrease heteroduplex formation, an additional 5 cycles of reconditioning PCR was added to the protocol. As a result, the products could be used for the DGGE experiment.

\section{DGGE electrophoresis}

Parallel DGGE analysis was performed for the CP/CPPS and infertility patients, using the D-Code universal mutation detection system apparatus (Bio-Rad, Hercules, CA, USA) with $16 \mathrm{~cm} \times 16 \mathrm{~cm} \times 1 \mathrm{~mm}$ gels according to the manufacturer's instructions. Sequence-specific separation of the PCR fragments was obtained in $8 \%(\mathrm{w} / \mathrm{v})$ polyacrylamide 
(acrylamide- $N, N^{\prime}$ bisacrylamide; 37.5:1 (w/v)) gels in $1 \times$ TAE buffer (40 mmol $\mathrm{l}^{-1}$ Tris, $20 \mathrm{mmol} \mathrm{l}^{-1}$ glacial acetic acid, $1 \mathrm{mmol} \mathrm{l}^{-1}$ EDTA, $\mathrm{pH}$ 8.0). The $16 \mathrm{~S}$ rRNA gene products of $\mathrm{V} 3$ were concentrated, and the concentration in each sample was determined by the EnSpire Multilabel Plate Reader (PerkinElmer, Waltham, MA, USA). Two hundred nanograms of each PCR product was applied to an $8 \%(\mathrm{w} / \mathrm{v})$ polyacrylamide gel with a $26.5 \%-52 \%$ denaturant gradient (100\% denaturant was $7 \mathrm{~mol}^{-1}$ urea and $40 \%$ deionized formamide). The DGGE marker was created by mixing 11 sequenced V3 fragments with the same universal primers, from top to bottom, the bands were stand for: Nitrosomonas europaea, Diaphorobacter nitroreducens, Bacteroidetes bacterium, Alpaproteobacterium PG-69, Hydrogenoplaga, Shingomonas spp, Paraccoas solventivorans, Thauera aromatica, Thiobacilus, Acidobactro and Nitrospira. Electrophoresis was performed in $1 \times$ Tris-EDTA buffer at $200 \mathrm{~V}$ at $60{ }^{\circ} \mathrm{C}$ for $4 \mathrm{~h}$. The gels were stained with SYBR Green I (Amresco, Solon, OH, USA) and photographed using a UVI gel documentation system (Tanon-3500; Tanon, Shanghai, China). DGGE graphs were analysed using Quantity One 1-D Analysis software (Bio-Rad).

\section{DGGE band sequencing}

The DGGE profiles were digitalized using Image J software. Through the use of Martens' uncertainty test followed by a one-way ANOVA, important DGGE bands (bands 1-4) were excised from the gel under UV illumination and incubated in $50 \mu$ Tris-EDTA buffer ( $\mathrm{pH} 8.0$ ) overnight at $4{ }^{\circ} \mathrm{C}$. The supernatant was used as a template for PCR with the primers described previously. The PCR products were purified using a PCR clean-up kit (Tiangen, Shanghai, China) and ligated into the pGEM-T Easy Vector (Takara). DH5 $\alpha$ cells (Tiangen) were then transformed with the plasmid. Positive clones were selected randomly. Inserts were re-amplified by PCR and screened by DGGE to verify their migration positions. Clones that migrated to the same position as the original DGGE bands were sequenced (Invitrogen, Shanghai, China). The sequences of excised DGGE bands were submitted to RDP II release 10 databases.

\section{Statistical analysis}

The numeric results are shown as mean \pm s.d. A one-way ANOVA was used to compare the average ages of the subjects in different groups. The 16S rRNA gene-positive rates in the different subject groups were compared using the Chi-squared test. For the time since diagnosis, we compared the category IIIA and IIIB samples using the independent $t$-test. All of the above statistical analyses were performed using SPSS software version 17.0. Based on digitalized DGGE profiles, the PCA analysis method was used to compare the EPS bacterial community structure in different groups. Partial least square discriminant analysis (PLS-DA) was used to discriminate each group, and leaveone-out cross-validation (LOOCV) was used to evaluate the correct classification rate of this PLS-DA model. To this end, Martens' uncertainty test was used, followed by a one-way ANOVA to select significant variable factors. The statistical analysis was performed in a MATLAB environment (version 7.1; MathWorks, Inc., Natick, MA, USA).

\section{RESULTS}

\section{Specimen collection and 16S rRNA gene detection}

For each subject, we collected clinical data including age, routine EPS test results, symptoms, time since diagnosis. Among all of the $\mathrm{CP} /$ CPPS patients, four of $29(13.79 \%)$ in category IIIB had prostatitis and three of $22(13.64 \%)$ category IIIA prostatitis patients were diagnosed as CPPS patients with the perineum as the sole location of pelvic pain. A one-way ANOVA was used to compare the average ages
( $P>0.05)$; there was no difference among the three patient groups. For the index of time since the diagnosis, we compared category IIIA and IIIB samples using the independent $t$-test $(P>0.05)$, which proved that the incidence of the disease had no correlation with the time since diagnosis. When we compared the $16 \mathrm{~S}$ rRNA gene-positive rate of the normal men and the patients using the Chi-squared test method, the three groups of patients had much higher 16S rRNA gene-positive rates compared with the normal men, while the $16 \mathrm{~S}$ rRNA genepositive rate did not differ significantly among the three patient groups (Table 1).

\section{EPS bacterial community structure was different in CP/CPPS patients and infertile patients}

To compare the EPS bacterial community structure of the CP/CPPS patients and the infertility patients, we randomly selected seven $16 \mathrm{~S}$ rRNA gene-positive samples from category IIIB prostatitis patients, seven 16 S rRNA gene-positive samples from category IIIA prostatitis patients and seven 16S rRNA gene-positive samples from infertile patients. The DGGE profiles showed that the dominant bands were distributed quite variably in different groups, with bands 1, 3 and 4 being found frequently in the CP/CPPS patient group (Figure 1a). PCA and PLS-DA analyses of the PCR-DGGE profiles indicated that the subjects in all three groups were clearly assembled to different districts (Figure 1b). We also compared each pair of groups using the PCA and PLS-DA analyses (Figure 2). Both analysis methods showed that the bacterial communities of the three groups differed. The accuracy of the PLS model was tested with the LOOCV analysis method, with dual factors of $92.9 \%$ between category IIIA and category IIIB patients, $100 \%$ between category IIIA and infertility patients, and $85.7 \%$ between category III prostatitis and infertility patients. Using a Martens' uncertainty test followed by the one-way ANOVA test, the three bands (1,3 and 4) were identified as the key variable factors for the discrepancy between CP/CPPS patients and infertile patients $(P<0.05)$.

EPS bacterial community structure differed between CP/CPPS patients with and without inflammation

To compare the EPS bacterial community structure of the CP/CPPS patients with and without inflammation, we randomly selected 17 samples from among the 16S rRNA gene-positive category IIIA prostatitis patients and 17 samples from $16 \mathrm{~S}$ rRNA gene-positive category IIIB prostatitis patients. The DGGE profiles showed that there were obviously different bacterial community structures in these two groups (Figure 3a), with bands 1 and 4 being more common in category IIIA prostatitis. The PCA and PLS-DA analyses were performed based on these DGGE profiles, and the subjects of these two groups could clearly be distinguished (Figure $\mathbf{3 b}$ ). The accuracy of the PLS

\section{Table 1 Demographics of the four groups of subjects ${ }^{a}$}

\begin{tabular}{lllll}
\hline Characteristics & Normal control $^{\text {}}$ & Infertility & Prostatitis IIIA & Prostatitis IIIB \\
\hline Number & 26 & 11 & 22 & 29 \\
Positive $^{\text {c }}$ & $4(15.38 \%) *$ & $9(81.82 \%)$ & $20(90.91 \%)$ & $25(86.21 \%)$ \\
Age(year) & $25.50 \pm 3.21$ & $31.09 \pm 3.32$ & $33.18 \pm 7.80$ & $34.03 \pm 7.01$ \\
Disease & NA & NA & $34.23 \pm 28.75$ & $26.20 \pm 17.32$ \\
$\quad$ time(month) & & & & \\
\hline
\end{tabular}

Abbreviation: NA, no applicable data.

a This table shows the characteristics of the subjects.

${ }^{\mathrm{b}}$ Normal control represents healthy men.

${ }^{c}$ Positive means 16S rRNA gene-positive numbers (percentage).

$* P<0.01$ compared with the three other patient groups. 
a

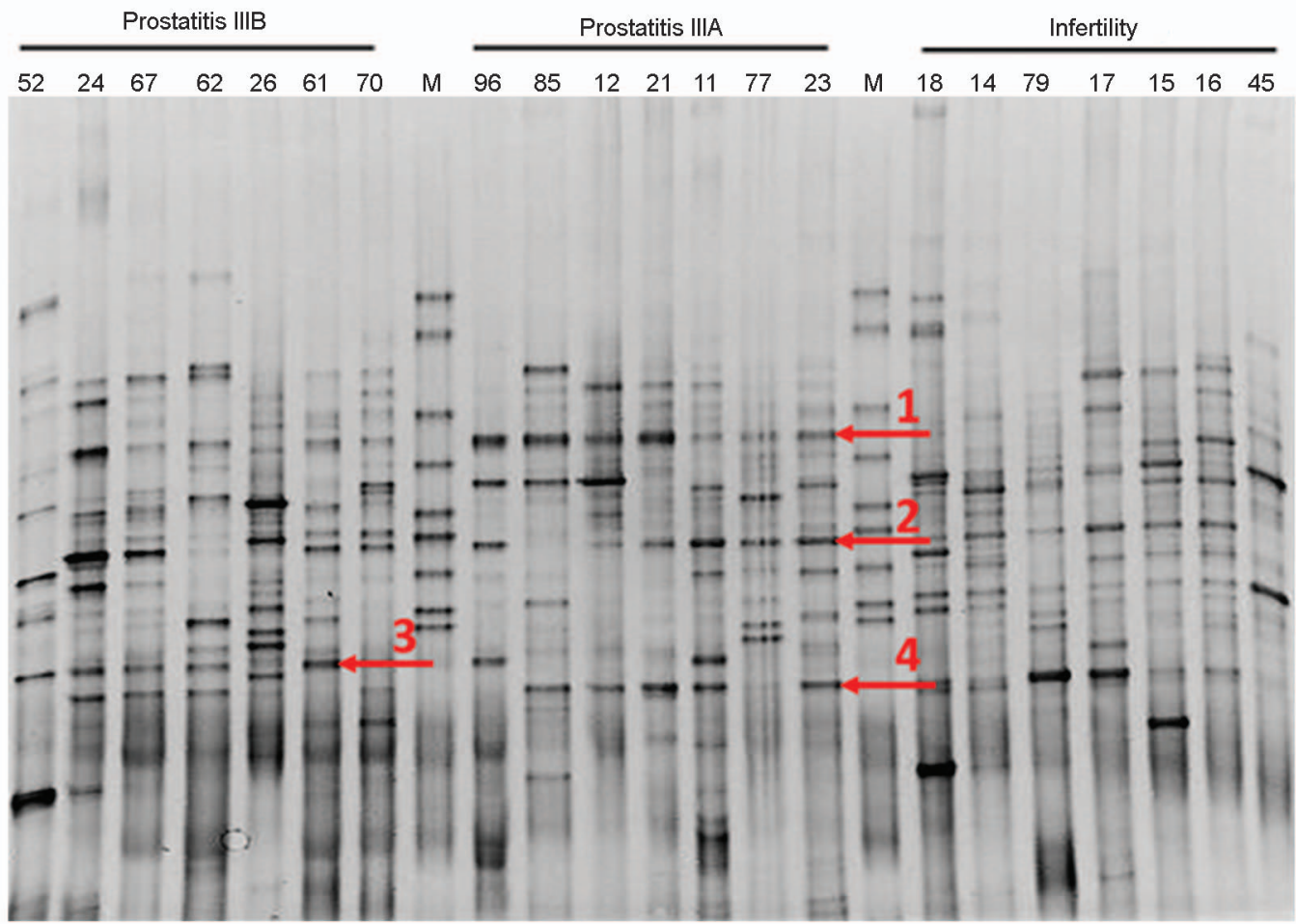

b
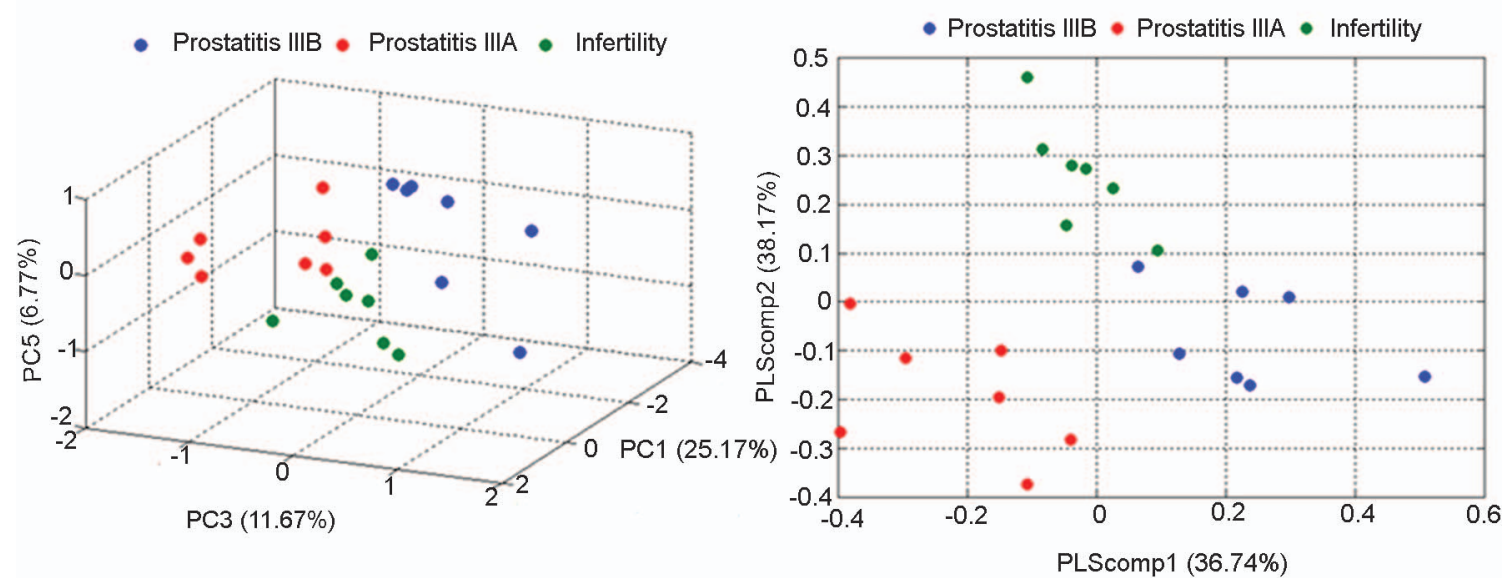

Figure 1 DGGE results and structural analyses for the three groups: prostatitis IIIA, prostatitis IIIB and infertility patients. DGGE, denaturing gradient gel electrophoresis; M, the markers for DGGE analysis; PC, principal component; PLScomp, partial least squares component.

model was checked using the LOOCV method, with $88.2 \%$ dual factors between category IIIA and category IIIB. Using Martens' uncertainty test followed by a one-way ANOVA, bands 1 and 4 were identified as priority factors in the discrepancy of category IIIA and category IIIB prostatitis patients $(P<0.05)$.

\section{Bacteria that played an important role in CP/CPPS}

The comparison analysis described above identified three bands ( 1,3 and 4) as the variable factors in discrimination of the three groups. Band 3 was frequently detected among patients with category IIIB prostatitis, while bands 1 and 4 were frequently detected in category IIIA prostatitis. Band 2 was detected at similar frequencies in all three groups. We excised and sequenced these four special bands. The results showed that bands 1 and 4 were $100 \%$ similar to uncultured bacteria clones, while band 2 was $100 \%$ similar to Bacillaceae (Family) and band 3 was $100 \%$ similar to Brevundimonas intermedia (Table 2).

\section{DISCUSSION}

In our research, the EPS $16 \mathrm{~S}$ rRNA gene-positive rate was higher in the $\mathrm{CP} / \mathrm{CPPS}$ and infertility patients than that reported by other studies on the detection of bacteria inhabiting the prostate. ${ }^{14,15,23,24}$ This may be due to our use of EPSs, while most other studies used prostate biopsy samples. ${ }^{14,15}$ The EPS is secreted by the prostate, so this type of body fluid may acquire bacteria after it passes through the lower part of the urethra. As a part of the male reproductive tract, the urethra is connected to the outside of the skin and the environment. Therefore, 
a

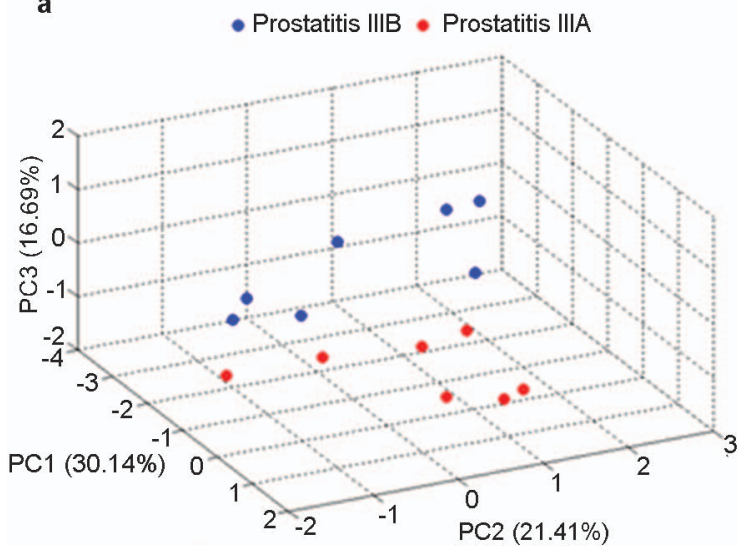

c

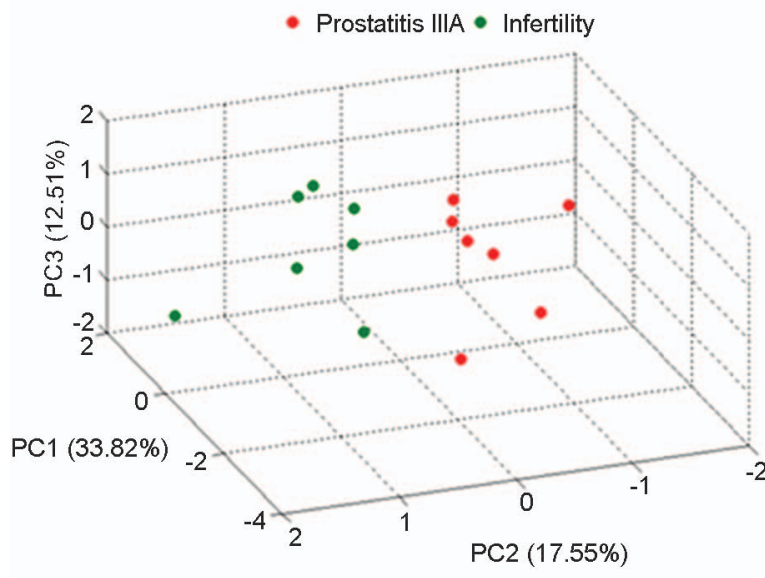

e

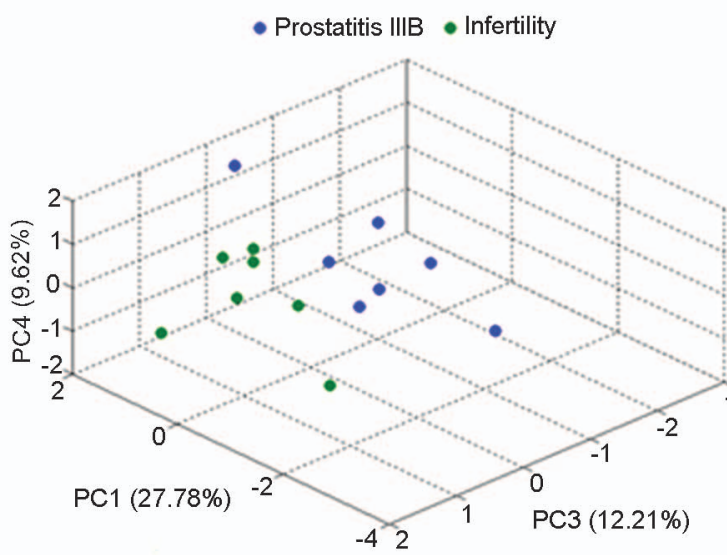

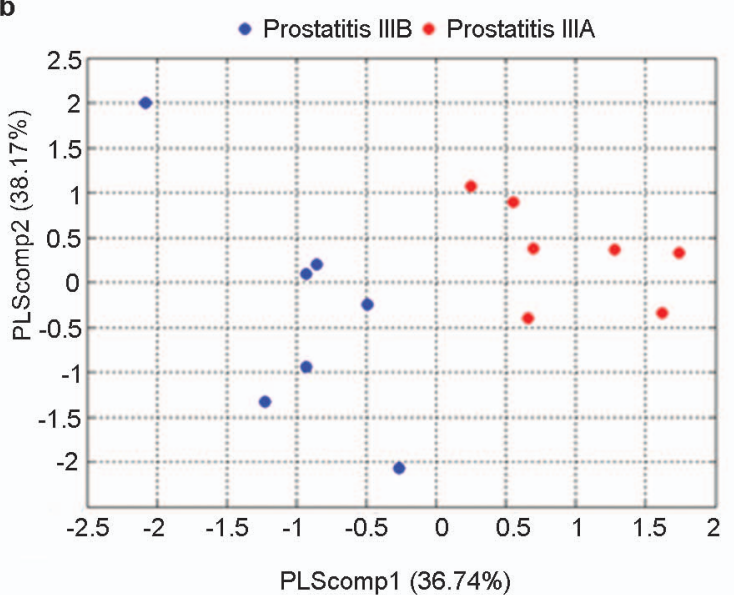

d
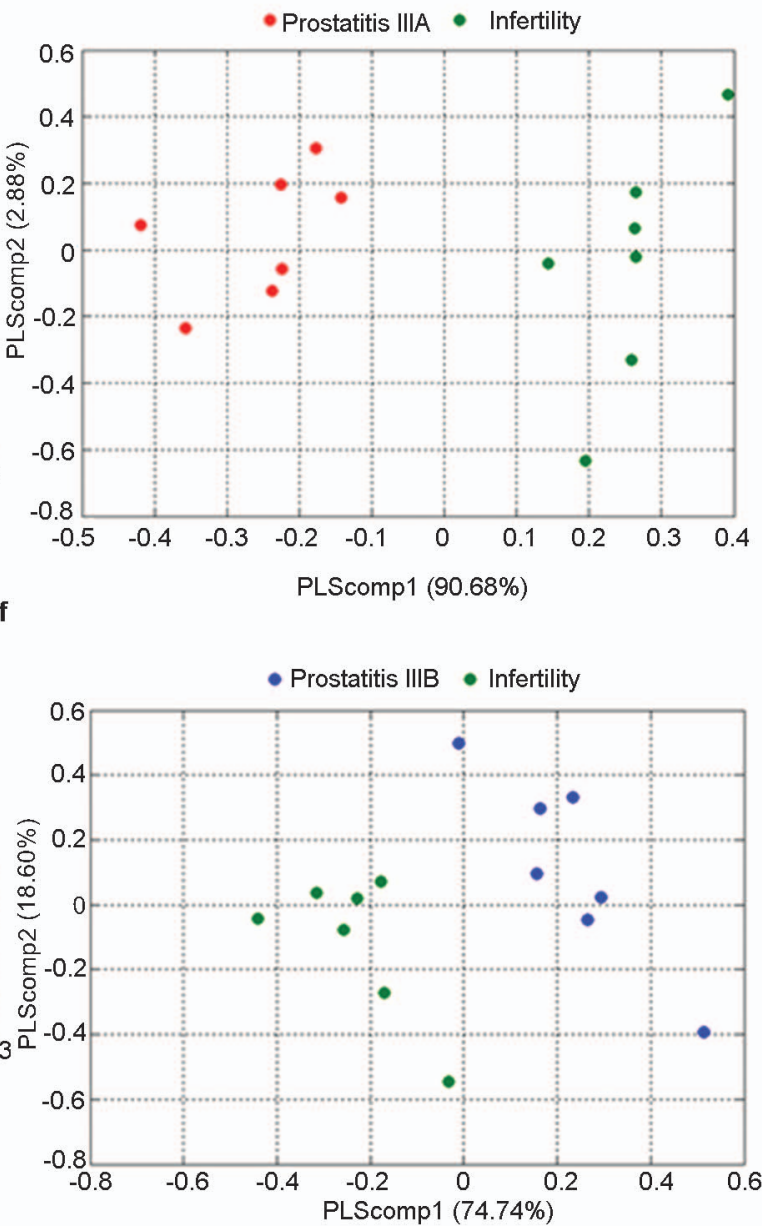

Figure 2 PCA and PLS-DA pairwise comparison of the DGGE profiles. According to the DGGE profiles in Figure 1a, we analysed the three groups including prostatitis IIIA, prostatitis IIIB and infertility patients using PCA and PLS analyses, two groups at a time. DGGE, denaturing gradient gel electrophoresis; PC, principal component; PCA, principal component analysis; PLScomp, partial least squares component; PLS-DA, partial least squares discriminant analysis.

bacteria on the skin outside the male reproductive tract could ascend to the urethra and the prostate. Furthermore, the DNA extraction method used, which involved exposure of the specimen to three types of enzymes to identify Gram-positive bacteria and disruption of the cells using the bead-beating method, may be another reason for the difference in the EPS 16 S rRNA gene-positive rate. These procedures are able to extract more DNA from the sample. The molecular fingerprint method we used was proven to be sensitive in detecting bacteria in the EPS from patients with and without prostatitis disease. ${ }^{14-16}$

The 16S rRNA gene-positive rate of the CP/CPPS patients was much higher than that among the normal men. This result indicated that both CP/CPPS and infertility were correlated with the existence of 
a

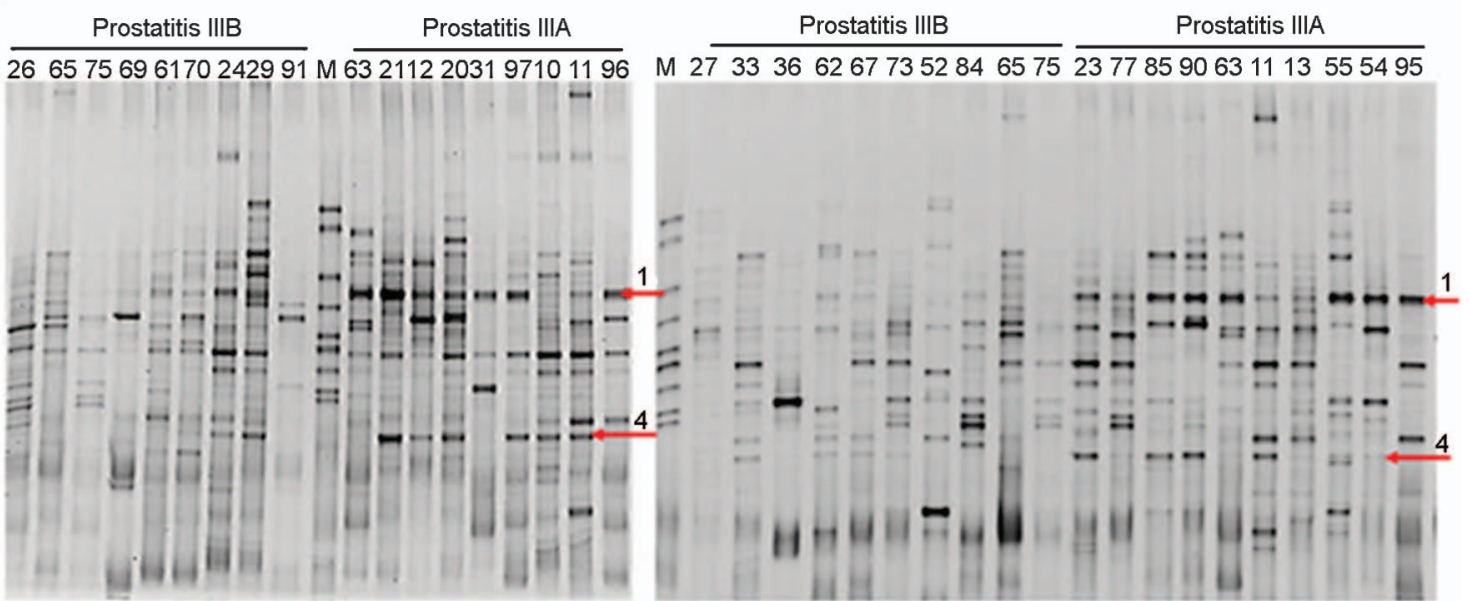

b
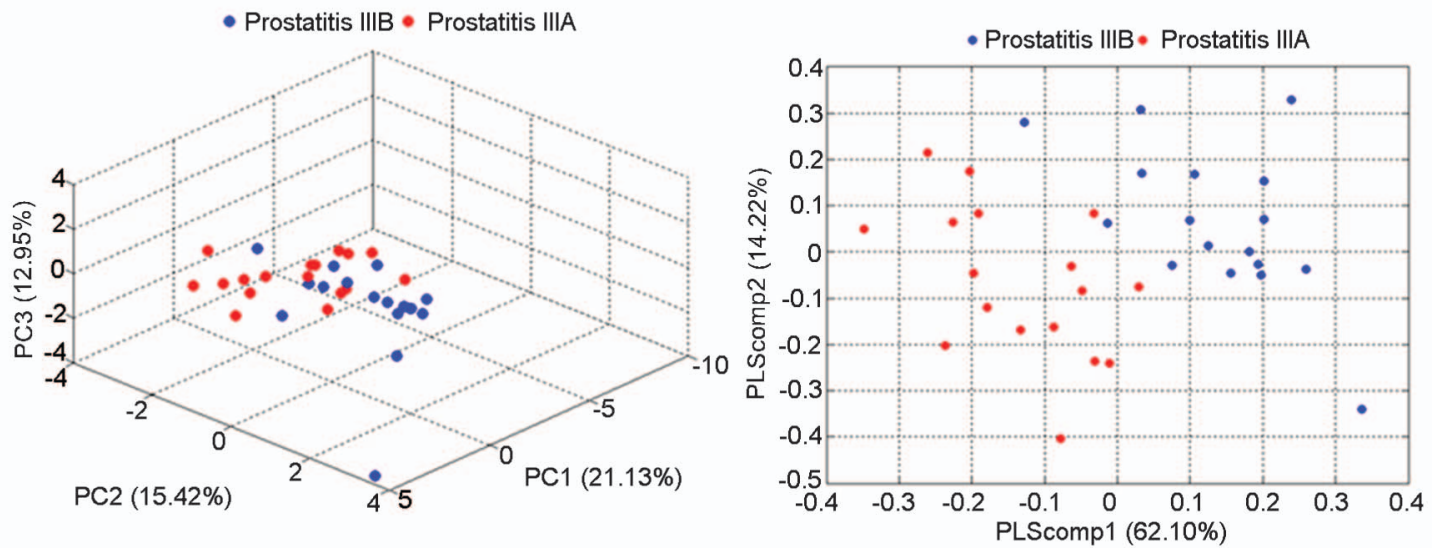

Figure 3 DGGE results and structural analyses of the two groups. DGGE profile of the EPS samples obtained from category IIIA and category IIIB prostatitis patients. DGGE, denaturing gradient gel electrophoresis; EPS, expressed prostatic secretion; M, the markers for PCA and PLS-DA analysis of the PCR-DGGE profiles; PC, principal component; PCA, principal component analysis; PLScomp, partial least squares component; PLS-DA, partial least squares discriminant analysis.

bacteria in the EPS. With the traditional culture method, the $\mathrm{CP} / \mathrm{CPPS}$ was usually diagnosed as chronic non-bacterial prostatitis. ${ }^{25,26}$ Because this sensitive molecular method has been used for the detection of bacteria, more studies have identified a relationship between bacteria and CP/CPPS disease. ${ }^{1,14,27}$ Previous research also showed that microbial communities distinct from those associated with prostatitis might be present at low levels in normal prostatic fluid. ${ }^{24}$ The $16 \mathrm{~S}$ rRNA gene-positive rate of the infertile patients was much higher than that of the normal men. Most of the infertility patients we collected were asthenospermia patients. This result indicates that the existence of bacteria in the male reproductive tract was correlated with male reproductive health. Many other researchers also showed that the presence of bacteria can influence sperm quality. ${ }^{28-31}$
Statistical analysis indicated that the positive rates were similar among all three patient groups. There was no difference in the $16 \mathrm{~S}$ rRNA gene-positive rate between CP/CPPS patients with and without inflammation. This result was consistent with other research, which proved that there was no significant association between the existence of bacteria and the histological evidence of inflammation associated with CP/CPPS disease. ${ }^{32}$ However, according to the statistical analysis based on the clinical data and the PCR-DGGE profiles, the structure of the EPS bacterial community differed among all three patient groups. The use of Martens' uncertainty test followed by a one-way ANOVA showed that three bands were identified as the key variable factors for the discrepancy of CP/CPPS and infertile patients, with bands 1 and 4 detected more frequently in category IIIA prostatitis. This finding was

\section{Table 2 Sequence identity of the four bands}

\begin{tabular}{llll}
\hline DGGE band & Phylogenic nearest neighbour & Accession no. & Index of sequence similarity \\
\hline 1 & Uncultured bacterium clone & FJ471462 & $100 \%$ \\
2 & Bacillaceae & FJ539123 & $100 \%$ \\
3 & Brevundimonas intermedia & AJ007802 & $100 \%$ \\
4 & Uncultured bacterium clone & GU940700 & $100 \%$ \\
\hline
\end{tabular}

Abbreviation: DGGE, denaturing gradient gel electrophoresis. 
consistent with results from the other researchers. This proved that the variety of the microorganisms was greater in CP/CPPS with inflammation than in the patients without inflammation. ${ }^{15,25,27,33,34}$ Even the category IV prostatitis patients harboured abundant microbiomes in their semen. ${ }^{35}$

Two types of bacteria were proven to play an important role in the development of category IIIA prostatitis. The sequencing result proved that these two types of bacteria were similar to the uncultured bacterium clone. The bacteria that play an important role in the development of category IIIA prostatitis may not have been cultured. Other researchers have shown that the prostate could harbour bacteria that cannot be detected with the traditional culture method. ${ }^{14}$ From these results, we concluded that particular types of bacteria exist in this part of the human body and that these types of bacteria are difficult to detect using traditional culture methods. Other studies also detected different types of bacteria in the prostate biopsy or EPS, and these bacteria were proven to differ from the bacteria existing in other parts of the human body. ${ }^{15,24}$ The ecology dysbiosis of the EPS bacterial flora might play an important role in the process of CP/CPPS with and without inflammation.

Band 3 was found more frequently in patients with category IIIB prostatitis. The sequencing results indicated that this band belongs to the genus Brevundimonas. It was usually detected in the environment, but was also infrequently isolated from clinical samples and therefore represents a potential human pathogen. ${ }^{36,37}$ The relationship between the genus Brevundimonas and category IIIB prostatitis deserves more research. Band 2 was evenly distributed in all three groups. The sequencing results proved that this type of bacteria belongs to the family Bacillaceae. Most such bacteria are non-pathogenic and may reside in the EPS.

Our research showed that the EPS bacterial community balance was one factor influencing male reproductive health. However, the presence of CP/CPPS disease was not determined solely based on the identification and counting of microorganisms. The microorganisms' parameters must also be estimated, possibly by the concentration of different bacterial substrains or the detection of opportunistic microorganisms with pathogenic properties, such as resistance to cationic antimicrobial peptides and the ability to inhibit the antimicrobial host defence factors. ${ }^{38}$ These opinions are also useful for the therapy of prostatitis, for example, fluoroquinolone-macrolide therapy results in pathogen eradication and chronic bacterial prostatitis symptom attenuation. This effect is dose-dependent. ${ }^{39}$ The relationship between the microbiome community and antibiotics will require further research.

The bacteria detected in the EPS were mostly derived from the skin outside the male reproductive tract. If they ascend to enter the human body, these bacteria could trigger innate immune responses. Certain pathogenic bacteria could trigger male reproductive disease, while most of the bacteria take a commensal role; these bacteria could functionally modulate the presence of inflammation. For example, researchers showed that the intestinal epithelium is immunologically quiescent, when it encounters commensal bacteria such as Bifidobacterium infantis or Lactobacillus salivarius. These commensal bacteria exert an antiinflammatory effect via the attenuation of proinflammatory transcription factor activation. ${ }^{40,41}$ Therefore, the commensal bacteria in the male reproductive tract might mediate male reproductive tract homoeostasis.

One prospective study suggested that prostatitis was correlated with an increased risk of benign prostatic hyperplasia and prostate cancer. ${ }^{6,7}$ Some researchers used prostatic tissue to show that the $16 \mathrm{~S}$
rRNA gene positive rate in CP/CPPS is similar to that among patients with localized prostate cancer. ${ }^{23}$ Future studies should be performed to investigate the role of bacterial community agents related to $\mathrm{CP} /$ CPPS in the development of prostate cancer.

In this study, we proved that most of the EPSs from CP/CPPS and infertility patients were $16 \mathrm{~S}$ rRNA gene-positive, which was not the case in normal men. EPS-related bacteria play an important role in the development of CP/CPPS and infertility. EPS bacterial community structure in the CP/CPPS patients differed from that observed in infertile men, as well as between CP/CPPS patients with and without inflammation. Three bands were identified as the key variables responsible for the discrepancy of CP/CPPS and infertile patients, with bands 1 and 4 identified as variable factors in the discrepancy of $\mathrm{CP} /$ CPPS with and without inflammation. The sequencing results showed that particular types of bacteria exist in the EPS and that these bacteria were not usually detected in other parts of the human body. We concluded that the ecological balance of the EPS microenvironment might play an important role in the manifestation of CP/CPPS with and without inflammation. Further research should be performed to detect any opportunistic, pathogenic bacteria in the EPS and investigate the potential molecular and cellular mechanisms underpinning the protective effect of the commensal bacterial and the destructive mechanism of the pathogenic bacteria.

\section{AUTHOR CONTRIBUTIONS}

CX conceived and designed the experiments, DSH, WML, and JS performed the experiments and analysed the data, XYP and LPZ participated in the design of the study and performed the statistical analysis. DSH and WML drafted the manuscript. DSH and WML contributed equally to this work. All authors read and approved the final manuscript.

\section{COMPETING FINANCIAL INTERESTS}

The authors declare that they have no competing financial interests.

\section{ACKNOWLEDGMENTS}

This work was supported by the Shanghai Leading Academic Discipline Project (S30201), the Shanghai Municipality Commission for Population and Family Planning (Bureau Authority Development Fund Project, 2009JG04), the Science and Technology Commission of Shanghai Municipality (10DZ2270600) and the Shanghai Basic Research Project (09DJ1400400). Mei-Ge Lu and Yan-Qin Hu provided technical support.

1 Domingue GJ Sr, Hellstrom WJ. Prostatitis. Clin Microbiol Rev 1998; 11: 604-13.

2 Schaeffer AJ. Clinical practice. Chronic prostatitis and the chronic pelvic pain syndrome. N Engl J Med 2006; 355: 1690-8.

3 Nickel JC. Prostatitis: diagnosis and classification. Curr Urol Rep 2003; 4: 259-60.

4 Nickel JC. Prostatitis: myths and realities. Urology 1998; 51: 362-6.

5 Liang CZ, Li HJ, Wang ZP, Xing JP, Hu WL et al. Treatment of chronic prostatitis in Chinese men. Asian J Androl 2009; 11: 153-6.

6 Krieger JN, Riley DE, Cheah PY, Liong ML, Yuen KH. Epidemiology of prostatitis: new evidence for a world-wide problem. World J Urol 2003; 21: 70-4.

7 Cheng I, Witte JS, Jacobsen SJ, Haque R, Quinn VP et al. Prostatitis, sexually transmitted diseases, and prostate cancer: the California Men's Health Study. PLoS One 2010; 5: e8736.

8 Lobel B, Rodriguez A. Chronic prostatitis: what we know, what we do not know, and what we should do! World J Urol 2003; 21: 57-63.

9 Krieger JN, Ross SO, Limaye AP, Riley DE. Inconsistent localization of Gram-positive bacteria to prostate-specific specimens from patients with chronic prostatitis. Urology 2005; 66: 721-5.

10 Jiang W, Jiang Y, Li C, Liang J. Investigation of supragingival plaque microbiota in different caries status of Chinese preschool children by denaturing gradient gel electrophoresis. Microb Ecol 2010; 61: 342-52.

11 Ling Z, Kong J, Liu F, Zhu H, Chen X et al. Molecular analysis of the diversity of vaginal microbiota associated with bacterial vaginosis. BMC Genomics 2010; 11: 488. 
12 Ravel J, Gajer P, Abdo Z, Schneider GM, Koenig SS et al. Microbes and Health Sackler Colloquium: Vaginal microbiome of reproductive-age women. Proc Natl Acad Sci USA e-pub ahead of print 3 June 2010; doi: 10.1073/pnas.1002611107.

13 Wei H, Dong L, Wang T, Zhang M, Hua W et al. Structural shifts of gut microbiota as surrogate endpoints for monitoring host health changes induced by carcinogen exposure. FEMS Microbiol Ecol 2010; 73: 577-86.

14 Riley DE, Berger RE, Miner DC, Krieger JN. Diverse and related 16S rRNA-encoding DNA sequences in prostate tissues of men with chronic prostatitis. J Clin Microbio 1998; 36: 1646-52.

15 Krieger JN, Riley DE, Roberts MC, Berger RE. Prokaryotic DNA sequences in patients with chronic idiopathic prostatitis. J Clin Microbiol 1996; 34: 3120-8.

16 Hochreiter WW, Duncan JL, Schaeffer AJ. Evaluation of the bacterial flora of the prostate using a 16S rRNA gene based polymerase chain reaction. J Urol 2000; 163: 127-30.

17 Shoskes DA, Shahed AR. Detection of bacterial signal by 16 S rRNA polymerase chain reaction in expressed prostatic secretions predicts response to antibiotic therapy in men with chronic pelvic pain syndrome. Tech Urol 2000; 6: 240-2.

18 Li M, Wang B, Zhang M, Rantalainen M, Wang S et al. Symbiotic gut microbes modulate human metabolic phenotypes. Proc Natl Acad Sci USA 2008; 105 2117-22.

19 Anderson RU, Weller C. Prostatic secretion leukocyte studies in non-bacterial prostatitis (prostatosis). J Urol 1979; 121: 292-4

20 Schaeffer AJ, Wendel EF, Dunn JK, Grayhack JT. Prevalence and significance of prostatic inflammation. J Urol 1981; 125: 215-9.

21 Zoetendal EG, von Wright A, Vilpponen-Salmela T, Ben-Amor K, Akkermans AD et al. Mucosa-associated bacteria in the human gastrointestinal tract are uniformly distributed along the colon and differ from the community recovered from feces. Appl Environ Microbiol 2002; 68: 3401-7.

22 Muyzer G, de Waal EC, Uitterlinden AG. Profiling of complex microbial populations by denaturing gradient gel electrophoresis analysis of polymerase chain reactionamplified genes coding for 16S rRNA. Appl Environ Microbiol 1993; 59: 695-700.

23 Keay S, Zhang CO, Baldwin BR, Alexander RB. Polymerase chain reaction amplification of bacterial 16s rRNA genes in prostate biopsies from men without chronic prostatitis. Urology 1999; 53: 487-91.

24 Tanner MA, Shoskes D, Shahed A, Pace NR. Prevalence of corynebacterial 16S rRNA sequences in patients with bacterial and 'nonbacterial' prostatitis. J Clin Microbiol 1999; 37: 1863-70.

25 Berger RE, Krieger JN, Kessler D, Ireton RC, Close C et al. Case-control study of men with suspected chronic idiopathic prostatitis. J Urol 1989; 141: 328-31.

26 Shortliffe LM, Sellers RG, Schachter J. The characterization of nonbacterial prostatitis: search for an etiology. J Urol 1992; 148: 1461-6.

27 Berger RE, Krieger JN, Rothman I, Muller CH, Hillier SL. Bacteria in the prostate tissue of men with idiopathic prostatic inflammation. J Urol 1997; 157: 863-5.
28 Berktas M, Aydin S, Yilmaz Y, Cecen K, Bozkurt H. Sperm motility changes after coincubation with various uropathogenic microorganisms: an in vitro experimental study. Int Urol Nephrol 2008; 40: 383-9.

29 Keck C, Gerber-Schafer C, Clad A, Wilhelm C, Breckwoldt M. Seminal tract infections: impact on male fertility and treatment options. Hum Reprod Update 1998; 4: 891903.

30 Chemes HE, Alvarez Sedo C. Tales of the tail and sperm head aches: changing concepts on the prognostic significance of sperm pathologies affecting the head, neck and tail. Asian J Androl 2012; 14: 14-23.

31 Zhou XP, Hu XL, Zhu YM, Qu F, Sun SJ et al. Comparison of semen quality and outcome of assisted reproductive techniques in Chinese men with and without hepatitis $\mathrm{B}$. Asian J Androl2011; 13: 465-9.

32 Sfanos KS, Sauvageot J, Fedor HL, Dick JD, de Marzo AM et al. A molecular analysis of prokaryotic and viral DNA sequences in prostate tissue from patients with prostate cancer indicates the presence of multiple and diverse microorganisms. Prostate 2008; 68: 306-20.

33 Krieger JN, Riley DE, Vesella RL, Miner DC, Ross SO et al. Bacterial DNA sequences in prostate tissue from patients with prostate cancer and chronic prostatitis. J Urol2000; 164: 1221-8.

34 Leskinen MJ, Rantakokko-Jalava K, Manninen R, Leppilahti M, Marttila T et al. Negative bacterial polymerase chain reaction (PCR) findings in prostate tissue from patients with symptoms of chronic pelvic pain syndrome (CPPS) and localized prostate cancer. Prostate 2003; 55: 105-10.

35 Korrovits P, Punab M, Turk S, Mandar R. Seminal microflora in asymptomatic inflammatory (NIH IV category) prostatitis. Eur Urol 2006; 50: 1338-44; discussion 1344-6.

36 Lee MR, Huang YT, Liao CH, Chuang TY, Lin CK et al. Bacteremia caused by Brevundimonas species at a tertiary care hospital in Taiwan, 2000-2010. Eur J Clin Microbiol Infect Dis 2011; 30: 1185-91.

37 Chi CY, Fung CP, Wong WW, Liu CY. Brevundimonas bacteremia: two case reports and literature review. Scand J Infect Dis 2004; 36: 59-61.

38 Ivanov IB, Gritsenko VA, Kuzmin MD. Phenotypic differences between coryneform bacteria isolated from seminal fluid of healthy men and men with chronic prostatitis syndrome. Asian J Androl 2009; 11: 517-20.

39 Magri V, Montanari E, Skerk V, Markotic A, Marras E et al. Fluoroquinolone-macrolide combination therapy for chronic bacterial prostatitis: retrospective analysis of pathogen eradication rates, inflammatory findings and sexual dysfunction. Asian J Androl 2011; 13: 819-27.

40 O'Mahony D, Murphy S, Boileau T, Park J, O'Brien F et al. Bifidobacterium animalis AHC7 protects against pathogen-induced NF-kappaB activation in vivo. BMC Immunol 2010; 11: 63.

41 O'Hara AM, O'Regan P, Fanning A, O'Mahony C, Macsharry J et al. Functional modulation of human intestinal epithelial cell responses by Bifidobacterium infantis and Lactobacillus salivarius. Immunology 2006; 118: 202-15. 